\title{
Serotonin-2A and 2C Receptor Gene Polymorphisms in Japanese Patients with Obstructive Sleep Apnea
}

\author{
Kunihiko SAKAI, Toshinori TAKADA, Hideaki NAKAYAMA, Yukiko KUBOTA, \\ Masami NAKAMATA*, Makoto SATOH**, Eiichi SUZUKI***, \\ Kohei AKAZAWA**** and Fumitake GEJYO
}

\begin{abstract}
Objective The serotonin (5-HT) $2 \mathrm{~A}$ and $2 \mathrm{C}$ receptor subtype plays an important role in the maintenance of upper airway stability and normal breathing in obesity. Polymorphisms in the 5-HT 2A receptor gene (HTR2A) and 5-HT 2C receptor gene (HTR2C) are associated with various diseases. The aim of this study was to investigate whether or not the HTR2A/C genotypes are associated with obstructive sleep apnea (OSA).

Methods The PCR-restriction fragment length polymorphism method was used to determine genotypes of the HTR2A/C gene. The genotype distributions and allele frequencies were statistically analyzed.

Subjects We studied 177 consecutive male patients with excessive daytime somnolence and an apnea plus hypopnea number [apnea-hypopnea index (AHI)] of greater than five per hour of sleep established by full polysomnography. One hundred Japanese men in whom OSA was clinically excluded were randomly selected as a control group.

Results Genotypes and allele frequencies of $102 \mathrm{~T} / \mathrm{C}$ polymorphism of the HTR2A and 796G/C polymorphism of the HTR2C did not differ between controls and patients with OSA. HTR2C polymorphism was considered inappropriate for association studies because of low frequency of the mutant allele. Multiple regression analysis showed that age and body mass index (BMI) were significantly associated with OSA, but HTR2A polymorphisms were not. HTR2A polymorphisms had no significant relationship with AHI or BMI, although further study with more samples will be needed for powerful statistical analyses.
\end{abstract}

Conclusions These results indicate that age and BMI, not these polymorphisms, are associated with OSA in this population.

(Internal Medicine 44: 928-933, 2005)

Key words: genetic susceptibility, obstructive sleep apnea, body mass index

\section{Introduction}

Obstructive sleep apnea (OSA) is a common form of sleep disordered breathing (SDB) and has been identified as an independent risk factor for several cardiovascular disease processes (1-4). The pathogenesis of OSA involves a collapsible upper airway dependent upon the upper airway dilator muscles for patency and normal respiration (5). While ventilation is normal in waking in patients with OSA, sleep-related reductions in motoneuronal activity of the upper-airway dilator result in collapse of the upper airway and apneas (6). Serotonin [5-hydroxytryptamine (5-HT)] is an important neurotransmitter that has a key role in controlling a large variety of sensory and motor functions. Genetic association has been reported between a synonymous $102 \mathrm{~T} / \mathrm{C}$ polymorphism in the gene encoding 5-HT 2A receptor (HTR2A) and a number of clinical phenotypes including schizophrenia (7, 8), clozapine response (9), psychotic symptoms in Alzheimer's disease (10), and certain features of depression (11). A human 5-HT 2C receptor gene (HTR2C) 796G/C polymorphism is related to CSF monoamine metabolite concentrations and DSM-III-R psychiatric diagnosis (12), clozapine response in schizophrenia (13), bipolar disorder (14), tardive dyskinesia in chronic schizophrenia (15), and the personality trait of reward dependence (16). However, the relationships

From the Division of Respiratory Medicine, Niigata University Graduate School of Medical and Dental Sciences, Niigata, *the Department of Internal Medicine, Niigata Rinko Hospital, Niigata, **the Department of Life and Health Education, Johetsu University of Education, Johetsu, ***the Department of General Medicine and ****the Department of Medical Informatics, Niigata University Medical and Dental Hospital, Niigata Received for publication November 9, 2004; Accepted for publication April 21, 2005

Reprint requests should be addressed to Dr. Toshinori Takada, the Division of Respiratory Medicine, Niigata University Graduate School of Medical and Dental Sciences, 1-757 Asahimachi-dori, Niigata 951-8510 


\section{HTR2A, HTR2C Polymorphisms in OSA}

between 796G/C polymorphism and behavior and drug response are still controversial.

Most functional studies show that 5-HT and serotonergic neurons have a significant excitatory effect on respiratory motoneurons, including upper airway motoneurons, both in vivo and in vitro, and that serotonergic neurons show maximal activity during wakefulness and minimal activity during REM sleep (17-19). Sleep-related withdrawal of 5HT at motoneurons contributes to the collapse of the upper airway and obstructive breathing $(20,21)$. We therefore hypothesized that these polymorphisms may be associated with OSA. Accordingly, we studied the polymorphisms of HTR2A and HTR2C in Japanese subjects with OSA.

\section{Methods}

\section{Subjects}

We studied 177 consecutive male patients with excessive daytime somnolence and with an apnea plus hypopnea number [apnea-hypopnea index (AHI)] of greater than five per hour of sleep. AHI score was established by full polysomnography (PSG). We excluded patients with renal failure, thyroid dysfunction, and psychiatric disorders. We also excluded patients 65 and older because the severity of SDB defined by obstructive events decreased and the prevalence of central sleep apnea increased past age 65 years (22).

One hundred Japanese men with a mean age of 38.7 years, who had requested annual physical examinations, were randomly selected as the control group. They did not have any abnormalities based on physical examination, chest radiography, electrocardiogram, urinalysis, and routine laboratory blood testing. In control subjects, OSA was excluded clinically by the criteria of Kapuniai et al (23). The control population consisted of unrelated ethnically matched subjects from the same area of Japan. The mean age and body mass index (BMI) of control subjects were lower than those of patients with OSA (Table 1).

All the subjects gave their written informed consent to participate in this study. The research was carried out in accordance with the Declaration of Helsinki (1989) of the World Medical Association, and the study was approved by the Committee of Ethics of Niigata University.

\section{Polysomnography}

Polysomnography [PSG (Somnostar, SensorMedics, Yorba Linda, CA)] was performed including measurements of electroencephalogram, electromyogram, electrooculogram, electrocardiogram, airflow by oronasal thermistor, chest and abdominal wall movements, oxygen saturation by pulse oxymeter, snoring sounds by tracheal microphone, and body position. PSG data were scored according to the standard criteria. The severity of sleep apnea was assessed by AHI, lowest oxygen saturation, cumulative percentage of sleep time with oxygen saturation below $90 \%$, and the average number of arousals per hour of sleep. AHI was used for association studies as a representative of severity of OSA.

\section{Determination of HTR2A and HTR2C genotypes}

DNA was extracted from whole peripheral blood by the standard method. For the HTR2A and HTR2C receptor genotyping, the polymerase chain reaction (PCR)-restriction fragment length polymorphism method was performed (24, 25). The $102 \mathrm{~T} / \mathrm{C}$ polymorphism in the HTR $2 \mathrm{~A}$ was detected using the oligonucleotide primers 5'-TCTGCTACAAGTTC TGGCTT-3' and 5'-CTGCAGCTTTTTCTCTAGGG-3' to amplify a 342-bp segment covering the polymorphic site. PCR was performed using denaturation at $94^{\circ} \mathrm{C}$ for 3 minutes, followed by 35 cycles at $94^{\circ} \mathrm{C}$ for 30 seconds, $45^{\circ} \mathrm{C}$ for 30 seconds, and $72^{\circ} \mathrm{C}$ for 60 seconds, and a final extension at $72^{\circ} \mathrm{C}$ for 3 minutes (DNA Thermal Cycler 9600; Perkin Elmer-Cetus, Norwalk, CT). The PCR products were digested with $2.0 \mathrm{U}$ of Msp I (New England Biolabs, Beverly, $\mathrm{MA})$ at $37^{\circ} \mathrm{C}$ for 2 hours, and run on a $2 \%$ ethidium bromide-agarose gel. Msp I digests the 342 bp DNA segment from CC homozygous individuals into 126 and $216 \mathrm{bp}$ fragments. DNA from TT homozygous individuals was not cut and DNA from CT heterozygous individuals shows the expected fragments at 342, 216, and $126 \mathrm{bp}$. For the polymorphism in the HTR2C, PCR primers: $5^{\prime}$-CTGCCATGATCA CAA-3' and 5'-GGCCTATTGGTTTGGCCAT-3' were employed. PCR was performed using denaturation at $94^{\circ} \mathrm{C}$ for 3 minutes, followed by 35 cycles at $94^{\circ} \mathrm{C}$ for 30 seconds, 58 ${ }^{\circ} \mathrm{C}$ for 30 seconds, and $72^{\circ} \mathrm{C}$ for 60 seconds, and a final extension at $72^{\circ} \mathrm{C}$ for 3 minutes. The PCR products were digested with $2.0 \mathrm{U}$ of Nla III (New England Biolabs) at $37^{\circ} \mathrm{C}$ for 2 hours, and run on a $4 \%$ ethidium bromide-NuSieve GTG (BioWhittaker Molecular Applications, East Rutherford, NJ) agarose gel. The restriction pattern was as follows: wild-type $130,30,20$, and $4 \mathrm{bp}$; mutant 150, 30, and $4 \mathrm{bp}$.

\section{Statistical analysis}

The genotype distributions and allele frequencies in two groups were analyzed with the chi-square test. The MannWhitney U test or Kruskal-Wallis test was used for unadjusted comparisons of age, BMI, and AHI between two or among three groups. The BMDP Statistical Package program (BMDP; Los Angeles, CA) was used for multivariate adjustments for all covariates, simultaneously, using the Cox regression analysis. The nQuery Advisor software (Statistical Solutions, Saugus, MA) was used to calculate power for the chi-square analyses. $\mathrm{P}$ values less than 0.05 were considered significant.

\section{Results}

Characteristics of study subjects are presented in Table 1. Age and BMI were significantly different between controls and patients with OSA. Genotype and allele frequencies of two polymorphisms in controls and OSA are shown in Table 2. As for HTR2A genotype of the 100 control subjects, 29 had the CC type, 46 the CT type, and 25 the TT genotype. Of the 177 OSA subjects, 40 had the CC type, 90 the CT type, and 47 the TT genotype. The frequencies of $\mathrm{C}$ allele in con- 
Table 1. Characteristics of Study Subjects

\begin{tabular}{llll}
\hline & $\begin{array}{l}\text { Controls } \\
(\mathrm{n}=100)\end{array}$ & $\begin{array}{l}\text { Patients } \\
(\mathrm{n}=177)\end{array}$ & $p$ value* \\
\hline Age, yr & & & \\
$\quad$ Mean \pm SD & $38.7 \pm 11.1$ & $48.3 \pm 10.1$ & $<0.001$ \\
Range & $21-63$ & $23-64$ & \\
AHI, events/h & NA & $46.1 \pm 25.8$ & \\
BMI, kg/m ${ }^{2}$ & & & \\
Mean $\pm S D$ & $21.7 \pm 2.3$ & $28.3 \pm 5.8$ & $<0.001$ \\
Range & $17.5-27.3$ & $19.4-77.0$ & \\
\hline
\end{tabular}

*Mann-Whitney U test. AHI: apnea hypopnea index, BMI: body mass index.

trol and OSA groups were $52.0 \%$ and $48.0 \%$, respectively. The genotype distribution and allele frequencies were not different between the groups. As for HTR2C genotype, of the 100 controls, 5 had the CC type, none the CG type, and 95 the GG genotype. Of the 160 OSA subjects, 6 had the CC type, none the CG type, and 154 the GG genotype. The frequencies of $\mathrm{C}$ allele in those groups were $5.0 \%$ and $3.8 \%$, respectively. The genotype distribution and allele frequencies were not different between the groups. The 796G/C polymorphism of the HTR2C gene was considered to be inappropriate for association studies because of the low frequency of the mutant allele in this population.

Multivariate analysis using Cox regression analysis on AHI was made with regard to the factors of age, BMI, and HTR2A genotype. Independent factors for AHI were age $(\mathrm{p}<0.001)$ and BMI $(\mathrm{p}<0.001)$. The HTR2A polymorphism was not included as a predictive variable (Table 3 ).

We then studied the relationships between HTR2A polymorphism and the severity of OSA, and between the polymorphism and BMI. HTR2A genotypes and alleles in mild and moderate OSA and severe OSA subjects according to the severity criteria are shown in Table 4 (26). Genotype and allele frequencies for HTR2A polymophism in nonobese $(\mathrm{BMI}<25)$ and obese $(25 \leqq \mathrm{BMI})$ subjects are summarized in Table 5 (27). The genotype distribution and allele frequencies were not different between the subjects grouped by severity of OSA or BMI. We next studied AHI and BMI in each genotype of the HTR2A (Table 6). Age, AHI, and BMI were not different among $40 \mathrm{CC}$ type, $90 \mathrm{CT}$ type, and 47 TT type of the HTR2A.

We finally calculated the statistical power of chi-square analyses in this study. The power of each analysis was less than $50 \%$ indicating that sample numbers were not sufficient to confirm a negative association of HTR2A polymophism with OSA.

\section{Discussion}

The present study showed a $102 \mathrm{~T} / \mathrm{C}$ polymorphism of the HTR2A and a 796G/C polymorphism of the HTR2C in Japanese subjects with OSA. Genotypes and allele frequen-
Table 2. Genotype and Allele Frequencies of Two Polymorphisms in Controls and OSA*

\begin{tabular}{lccc}
\hline Polymorphism & $\begin{array}{c}\text { Control } \\
(\mathrm{n}=100)\end{array}$ & $\begin{array}{c}\text { OSA } \\
(\mathrm{n}=177)\end{array}$ & $p$ Value $^{\dagger}$ \\
\hline 5HT2A 102T/C & & & \\
Genotypes & & & \\
CC & $29(29.0)$ & $40(22.6)$ & 0.493 \\
CT & $46(46.0)$ & $90(50.8)$ & \\
TT & $25(25.0)$ & $47(26.6)$ & \\
Alleles & & & \\
C & $104(52.0)$ & $170(48.0)$ & 0.369 \\
T & $96(48.0)$ & $184(52.0)$ & \\
5HT2C 796G/C & & & \\
Genotypes & & & \\
CC & $5(5.0)$ & $6(3.8)$ & 0.626 \\
GG & $95(95.0)$ & $154(96.2)$ & \\
Alleles & & & \\
C & $10(5.0)$ & $12(3.8)$ & 0.491 \\
G & $190(95.0)$ & $308(96.2)$ & \\
\hline
\end{tabular}

*Values in parentheses are percentages. Chi-square analysis. ${ }^{*}$ Genotypes of HTR2C were not determined in 17 OSA subjects for technical reasons. OSA: obstructive sleep apnea, HTR2A: serotonin-2A receptor gene, HTR2C: serotonin-2C receptor gene.

Table 3. Multiple Regression Model on AHI for All Subjects

\begin{tabular}{lccc}
\hline \multicolumn{1}{c}{ Factors } & Coefficient & SE of regression & $p$ value \\
\hline Age, year & 0.096 & 0.020 & $<0.001$ \\
BMI, kg/m & 0.663 & 0.091 & $<0.001$ \\
Constant & -19.963 & 2.519 & $<0.001$ \\
\hline
\end{tabular}

OSA: obstructive sleep apnea, SE: standard error, BMI: body mass index.

Table 4. Severity of AHI and HTR2A Genotypes and Alleles*

\begin{tabular}{|c|c|c|c|}
\hline & $\begin{array}{c}5 \leqq \mathrm{AHI}<30 \\
(\mathrm{n}=59)\end{array}$ & $\begin{array}{l}30 \leqq \mathrm{AHI} \\
(\mathrm{n}=118)\end{array}$ & $p$ Value \\
\hline AHI $($ Mean \pm SD $)$ & $18.2 \pm 7.6$ & $46.1 \pm 25.8$ & \\
\hline BMI $($ Mean \pm SD $)$ & $27.6 \pm 7.9$ & $28.3 \pm 5.8$ & $0.002^{\dagger}$ \\
\hline \multicolumn{4}{|l|}{ Genotypes } \\
\hline $\mathrm{CC}$ & $14(23.7)$ & $26(22.0)$ & $0.946^{+}$ \\
\hline $\mathrm{CT}$ & $29(49.2)$ & $61(51.7)$ & \\
\hline TT & $16(27.1)$ & $31(26.3)$ & \\
\hline \multicolumn{4}{|l|}{ Alleles } \\
\hline $\mathrm{C}$ & $57(48.3)$ & $113(47.9)$ & $0.940^{\ddagger}$ \\
\hline $\mathrm{T}$ & $61(51.7)$ & $123(52.1)$ & \\
\hline
\end{tabular}

*Values in parentheses are percentages. Mann-Whitney $\mathrm{U}$ test. ${ }^{*}$ Chi-square test for difference in genotypic or allelic proportions between mild and moderate OSA and severe OSA subjects. AHI: apnea hypopnea index, HTR2A: serotonin-2A receptor gene, BMI: body mass index. 


\section{HTR2A, HTR2C Polymorphisms in OSA}

Table 5. HTR2A and Genotypes and Alleles in Nonobese and Obese Subjects*

\begin{tabular}{|c|c|c|c|}
\hline & $\begin{array}{c}\text { BMI<25 } \\
(n=48)\end{array}$ & $\begin{array}{c}25 \leqq B M I \\
(n=129)\end{array}$ & $p$ Value \\
\hline BMI $($ Mean \pm SD) & $23.2 \pm 1.2$ & $30.2 \pm 5.7$ & \\
\hline AHI $($ Mean \pm SD) & $34.8 \pm 20.3$ & $50.3 \pm 26.5$ & $0.007^{\dagger}$ \\
\hline \multicolumn{4}{|l|}{ Genotypes } \\
\hline & CT $24(50.0)$ & $66(51.2)$ & 0.990 \\
\hline & TT $13(27.1)$ & $34(26.3)$ & \\
\hline \multicolumn{4}{|l|}{ Alleles } \\
\hline & C $46(44.3)$ & $124(48.9)$ & $0.981^{*}$ \\
\hline & T $50(55.7)$ & $134(51.1)$ & \\
\hline
\end{tabular}

*Values in parentheses are percentages. ${ }^{\dagger}$ Mann-Whitney U test. ${ }^{*}$ Chi-square test for difference in genotypic or allelic proportions between nonobese and obese subjects. HTR2A: serotonin-2A receptor gene, BMI: body mass index, AHI: apnea hypopnea index.

Table 6. AHI and BMI in Each Genotype of the HTR2A Gene

\begin{tabular}{lllll}
\hline & \multicolumn{3}{c}{ HTR2A genotype } & \\
\cline { 2 - 4 } & \multicolumn{1}{c}{$\begin{array}{c}\mathrm{CC} \\
(\mathrm{n}=40)\end{array}$} & \multicolumn{1}{c}{$\begin{array}{c}\mathrm{CT} \\
(\mathrm{n}=90)\end{array}$} & $\begin{array}{c}\mathrm{TT} \\
(\mathrm{n}=47)\end{array}$ & $p$ Value* \\
\hline Age & $48.5 \pm 9.7$ & $48.6 \pm 10.5$ & $47.7 \pm 9.9$ & 0.8606 \\
AHI & $51.7 \pm 30.6$ & $43.9 \pm 23.6$ & $45.6 \pm 25.4$ & 0.5082 \\
BMI & $28.4 \pm 4.6$ & $28.6 \pm 6.8$ & $27.7 \pm 4.3$ & 0.8340 \\
\hline
\end{tabular}

Means and standard deviations are indicated. *Kruskal-Wallis test. AHI: apnea hypopnea index, BMI: body mass index, HTR2A: serotonin-2A receptor gene.

cies of the SNPs were not different between controls and OSA patients. Multivariate analysis on AHI revealed that independent factors for AHI were age and BMI and the HTR2A polymorphism was not a predictive variable.

OSA is characterized by recurrent sleep-induced collapse of the pharyngeal airway leading to hypoxemia and hypercapnia. Variables tending to promote pharyngeal collapse include negative pressure within the airway (eg, during inspiration) and positive pressure outside the airway (eg, fat deposition, small mandible) (6). Patency of the human upper airway is maintained mostly by muscle activation and soft tissue structures. The activity of the muscles responsible for maintaining patency of the upper airway is increased during inspiration, thus stiffening and dilating the upper airway and acting to counteract the collapsing influence of negative airway pressure (28). During sleep there is loss of both tonic premotor input (and neuromuscular compensation) and reflex driven muscle activation leading to a large decrement in electromyogram and ultimately airway collapse. 5-HT plays an important role in the patency of the upper airway. 5-HT excites adult upper airway dilator motor neurons $(17,18)$ and provides intrinsic excitation at brainstem motor neurons in unanesthetized animals (19). The activity of neurons supplying 5-HT to motor neurons declines in sleep $(20,21)$. Furthermore, pretreatment of upper airway dilator motor neurons with 5-HT reduces sleep state-dependent suppression in upper airway dilator muscle activity (29).

5 -HT acts through a large family of receptors (30). The 5HT $2 \mathrm{~A} / 2 \mathrm{C}$ receptor subtype plays an important role in the maintenance of upper airway stability and normal breathing in obesity. 5-HT 2A is the predominant excitatory 5-HT receptor subtype at the hypoglossal motor neurons (31). Polymorphisms in the HTR2A and HTR2C are associated with various diseases. There was, however, no association of HTR2A 102T/C and HTR2C 796G/C polymorphisms and the development of OSA in the present study. A recent study employing a highly accurate quantitative allele-specific primer extension assay suggests that the HTR2A locus is unlikely to contain common polymorphisms or epigenetic modification that alters HTR2A mRNA levels in adult brain (32). Although 5-HT 2A receptor predominantly contributes to 5-HT excitation within a representative upper airway motor nucleus, lack of common polymorphisms or epigenetic modification that alters HTR2A mRNA levels might be the reason for the absence of an association of the 102T/C polymorphism with $\mathrm{AHI}$ in this population. The serotonin $2 \mathrm{C}$ excitatory effects are of lower magnitude (31). Although 796G/C polymorphism of the HTR2C was functional (33), the effect of an active allele of the polymorphism might not be sufficient for the SNP to be associated with AHI because of less dominance of the subtype in the hypoglossal nucleus.

The variability in airway size is probably determined by genetic influences on bony structure, tongue size and tonsillar tissue as well as acquired factors such as obesity. Obesity may affect pharyngeal size by fat deposition around the upper airway or by altering muscle orientation and function. Narrowing of the pharyngeal airway as a result of alterations in craniofacial morphology has also been suggested in the etiology of OSA (34). A number of factors combine to determine airway size which has an impact on the propensity for pharyngeal collapse and apnea during sleep. Although genetic polymorphisms of the HTR2A and HTR2C genes may play an important role in the activity of the pharyngeal dilator muscles, other variables such as cephalometric features and soft tissue structures might be determinants for patency of the human upper airway during sleep.

Kadotani and colleagues reported an association between the ApoE\&4 allele and SDB in a study of 791 Caucasian adults in Wisconsin (35). However, others could not replicate their results in different genetic populations $(36,37)$. Recently, a whole genome scan for OSA and obesity in African-American families identified a candidate region on chromosome 8q for linkage to the AHI (38). HTR2A and HTR2C are on chromosome $13 \mathrm{q}$ and $\mathrm{Xq}$, respectively, and not on chromosome 8q. Comparison of Far-East Asian men with Caucasian men demonstrated that Asian men had greater severity of OSA and less obesity suggesting the etiology of sleep disordered breathing in Asians may differ 
from that of Caucasians (39). Therefore, the results of the whole genome scan should be further reconfirmed in patients with SDB of different races.

This is the first report to study genetic association of HTR2A and HTR2C with SDB. There are some limitations to our study. The present study was not powerful enough to confirm a negative association between the HTR2A polymorphism and OSA. Our controls have not undergone PSG and OSA was clinically excluded by the criteria of self report scores by Kapuniai et al (23). which can correctly identify $70-76 \%$ of sleep apnea cases with AHI $>5$ with predictive accuracy of $88 \%$ for AHI $>10$. Our control group might represent Japanese male subjects without OSA, but a further study with a larger number of patients with OSA and control subjects whose AHI was proved to be less than five by PSG should be performed.

Acknowledgements: The authors thank Ms. Minowa and Ms. Furui for help in extracting DNA from clinical specimens.

\section{References}

1) Nieto FJ, Young TB, Lind BK, et al. Association of sleep-disordered breathing, sleep apnea, and hypertension in a large community-based study. Sleep Heart Health Study. JAMA 283: 1829-1836, 2000.

2) Peppard PE, Young T, Palta M, Skatrud J. Prospective study of the association between sleep-disordered breathing and hypertension. N Engl J Med 342: 1378-1384, 2000.

3) Peker Y, Hedner J, Kraiczi H, Loth S. Respiratory disturbance index: an independent predictor of mortality in coronary artery disease. Am J Respir Crit Care Med 162: 81-86, 2000.

4) Shahar E, Whitney CW, Redline S, et al. Sleep-disordered breathing and cardiovascular disease: cross-sectional results of the Sleep Heart Health Study. Am J Respir Crit Care Med 163: 19-25, 2001.

5) Suratt PM, Dee P, Atkinson RL, Armstrong P, Wilhoit SC. Fluoroscopic and computed tomographic features of the pharyngeal airway in obstructive sleep apnea. Am Rev Respir Dis 127: 487-492, 1983.

6) Remmers JE, deGroot WJ, Sauerland EK, Anch AM. Pathogenesis of upper airway occlusion during sleep. J Appl Physiol 44: 931-938, 1978.

7) Inayama $\mathrm{Y}$, Yoneda $\mathrm{H}$, Sakai $\mathrm{T}$, et al. Positive association between a DNA sequence variant in the serotonin $2 \mathrm{~A}$ receptor gene and schizophrenia. Am J Med Genet 67: 103-105, 1996.

8) Williams J, McGuffin P, Nothen M, Owen MJ. Meta-analysis of association between the 5-HT2a receptor T102C polymorphism and schizophrenia. EMASS Collaborative Group. European Multicentre Association Study of Schizophrenia. Lancet 349: 1221, 1997.

9) Arranz MJ, Munro J, Sham P, et al. Meta-analysis of studies on genetic variation in 5-HT2A receptors and clozapine response. Schizophr Res 32: 93-99, 1998.

10) Holmes C, Arranz MJ, Powell JF, Collier DA, Lovestone S. 5-HT2A and 5-HT2C receptor polymorphisms and psychopathology in late onset Alzheimer's disease. Hum Mol Genet 7: 1507-1509, 1998.

11) Arias B, Gutierrez B, Pintor L, Gasto C, Fananas L. Variability in the 5-HT(2A) receptor gene is associated with seasonal pattern in major depression. Mol Psychiatry 6: 239-242, 2001.

12) Lappalainen J, Long JC, Virkkunen M, Ozaki N, Goldman D, Linnoila M. HTR2C Cys23Ser polymorphism in relation to CSF monoamine metabolite concentrations and DSM-III-R psychiatric diagnoses. Biol Psychiatry 46: 821-826, 1999.

13) Sodhi MS, Arranz MJ, Curtis D, et al. Association between clozapine response and allelic variation in the 5-HT2C receptor gene. Neuroreport 7: 169-172, 1995.
14) Lerer B, Macciardi F, Segman RH, et al. Variability of 5-HT2C receptor cys23ser polymorphism among European populations and vulnerability to affective disorder. Mol Psychiatry 6: 579-585, 2001.

15) Segman RH, Heresco-Levy U, Finkel B, et al. Association between the serotonin $2 \mathrm{C}$ receptor gene and tardive dyskinesia in chronic schizophrenia: additive contribution of 5-HT2Cser and DRD3gly alleles to susceptibility. Psychopharmacology (Berl) 152: 408-413, 2000.

16) Ebstein RP, Segman R, Benjamin J, Osher Y, Nemanov L, Belmaker RH. 5-HT2C (HTR2C) serotonin receptor gene polymorphism associated with the human personality trait of reward dependence: interaction with dopamine D4 receptor (D4DR) and dopamine D3 receptor (D3DR) polymorphisms. Am J Med Genet 74: 65-72, 1997.

17) Douse MA, White DP. Serotonergic effects on hypoglossal neural activity and reflex responses. Brain Res 726: 213-222, 1996.

18) Bayliss DA, Viana F, Talley EM, Berger AJ. Neuromodulation of hypoglossal motoneurons: cellular and developmental mechanisms. Respir Physiol 110: 139-150, 1997.

19) Ribeiro-do-Valle LE, Metzler CW, Jacobs BL. Facilitation of masseter EMG and masseteric (jaw-closure) reflex by serotonin in behaving cats. Brain Res 550: 197-204, 1991.

20) McGinty DJ, Harper RM. Dorsal raphe neurons: depression of firing during sleep in cats. Brain Res 101: 569-575, 1976.

21) Heym J, Steinfels GF, Jacobs BL. Activity of serotonin-containing neurons in the nucleus raphe pallidus of freely moving cats. Brain Res 251: 259-276, 1982.

22) Bixler EO, Vgontzas AN, Ten Have T, Tyson K, Kales A. Effects of age on sleep apnea in men: I. Prevalence and severity. Am J Respir Crit Care Med 157: 144-148, 1998.

23) Kapuniai LE, Andrew DJ, Crowell DH, Pearce JW. Identifying sleep apnea from self-reports. Sleep 11: 430-436, 1988.

24) Chen RY, Sham P, Chen EY, et al. No association between T102C polymorphism of serotonin-2A receptor gene and clinical phenotypes of Chinese schizophrenic patients. Psychiatry Res 105: 175-185, 2001.

25) Serretti A, Lilli R, Lorenzi C, Lattuada E, Smeraldi E. Serotonin-2C and serotonin-1A receptor genes are not associated with psychotic symptomatology of mood disorders. Am J Med Genet 96: 161-166, 2000.

26) Sleep-related breathing disorders in adults: recommendations for syndrome definition and measurement techniques in clinical research. The Report of an American Academy of Sleep Medicine Task Force. Sleep 22: 667-689, 1999.

27) Kanazawa M, Yoshiike N, Osaka T, Numba Y, Zimmet $P$, Inoue $S$. Criteria and classification of obesity in Japan and Asia-Oceania. Asia Pac J Clin Nutr 11 Suppl 8: S732-S737, 2002.

28) van Lunteren E. Muscles of the pharynx: structural and contractile properties. Ear Nose Throat J 72: 27-29, 33, 1993.

29) Jelev A, Sood S, Liu H, Nolan P, Horner RL. Microdialysis perfusion of 5-HT into hypoglossal motor nucleus differentially modulates genioglossus activity across natural sleep-wake states in rats. J Physiol 532: 467-481, 2001

30) Barnes NM, Sharp T. A review of central 5-HT receptors and their function. Neuropharmacology 38: 1083-1152, 1999.

31) Fenik P, Veasey SC. Pharmacological characterization of serotonergic receptor activity in the hypoglossal nucleus. Am J Respir Crit Care Med 167: 563-569, 2003.

32) Bray NJ, Buckland PR, Hall H, Owen MJ, O'Donovan MC. The serotonin-2A receptor gene locus does not contain common polymorphism affecting mRNA levels in adult brain. Mol Psychiatry 9: 109114, 2004.

33) Okada M, Northup JK, Ozaki N, Russell JT, Linnoila M, Goldman D. Modification of human 5-HT(2C) receptor function by Cys23Ser, an abundant, naturally occurring amino-acid substitution. Mol Psychiatry 9: 55-64, 2004.

34) Partinen M, Guilleminault C, Quera-Salva MA, Jamieson A. Obstructive sleep apnea and cephalometric roentgenograms. The role of anatomic upper airway abnormalities in the definition of abnormal breathing during sleep. Chest 93: 1199-1205, 1988. 


\section{HTR2A, HTR2C Polymorphisms in OSA}

35) Kadotani H, Kadotani T, Young T, et al. Association between apolipoprotein E epsilon4 and sleep-disordered breathing in adults. JAMA 285: 2888-2890, 2001.

36) Foley DJ, Masaki K, White L, Redline S. Relationship between apolipoprotein E epsilon4 and sleep-disordered breathing at different ages. JAMA 286: 1447-1448, 2001.

37) Saarelainen S, Lehtimaki T, Kallonen E, Laasonen K, Poussa T, Nieminen MM. No relation between apolipoprotein $\mathrm{E}$ alleles and ob- structive sleep apnea. Clin Genet 53: 147-148, 1998.

38) Palmer LJ, Buxbaum SG, Larkin EK, et al. Whole genome scan for obstructive sleep apnea and obesity in African-American families. Am J Respir Crit Care Med 169: 1314-1321, 2004.

39) Li KK, Kushida C, Powell NB, Riley RW, Guilleminault C. Obstructive sleep apnea syndrome: a comparison between Far-East Asian and white men. Laryngoscope 110: 1689-1693, 2000. 